\title{
Association between the atherogenic index of plasma and major adverse cardiovascular events among non-diabetic hypertensive elderly patients
}

\section{Fei Hang}

Department of Cardiology, Beijing Anzhen hospital, Capital Medical University, Beijing, China Jieruo Chen

Department of Cardiology, Beijing Anzhen hospital, Capital Medical University, Beijing, China

\section{Zefeng Wang}

Department of Cardiology, Beijing Anzhen hospital, Capital Medical University, Beijing, China

\section{Keyang Zheng}

Department of Cardiology, Beijing Anzhen hospital, Capital Medical University, Beijing, China

\section{Yongquan Wu ( $\nabla$ wuyongquan_anzhen@163.com )}

Department of Cardiology, Beijing Anzhen hospital, Capital Medical University, Beijing, China

\section{Research Article}

Keywords: atherogenic index of plasma, major adverse cardiovascular events, hypertension, intensive blood pressure management

Posted Date: January 27th, 2022

DOI: https://doi.org/10.21203/rs.3.rs-1282126/v1

License: (c) (1) This work is licensed under a Creative Commons Attribution 4.0 International License. Read Full License 


\section{Abstract}

Background: The literature on the association between the atherogenic index of plasma (AIP) with the risk of major adverse cardiovascular events (MACEs) among non-diabetic hypertensive elderly patients is quite limited at present.

Methods: We performed a post-hoc analysis of data obtained from the Systolic Blood Pressure Intervention Trial (SPRINT) and explored the predictive value of AIP on the risk of MACEs among nondiabetic hypertensive elderly patients, to evaluate whether the benefit of intensive blood pressure control in preventing MACEs is stable in different AIP subgroups.

Results: 9,323 participants with AIP were included in this analysis, and $561(6.02 \%)$ participants had composite cardiovascular outcomes during a median of 3.22 years of follow-up. The subjects in the highest quartile of AIP had a significantly increased risk of the primary outcome. In the fully adjusted Model 3, the adjusted HRs of the primary outcome for participants in Q2, Q3, and Q4 of AIP were 1.32 $(1.02,1.72), 1.38(1.05,1.81)$, and $1.56(1.17,2.08)$ respectively. Consistently, the trend test for the association between AIP quartiles and the primary outcome showed that a higher AIP quartile was associated with a significantly higher risk of the primary outcome (adjusted HR $(95 \% \mathrm{Cl})$ in Model 3: 1.14 $(1.04,1.25), P=0,004)$. However, within each AIP quartile, absolute event rates were lower for the intensive treatment group. No evidence was found for the interaction of intensive blood pressure control and AIP for the risk of the primary outcome (P for interaction $=0.932)$.

Conclusion: This study found that elevated AIP is independently and positively associated with the risk of MACEs among non-diabetic elderly hypertensive patients. The benefit of intensive blood pressure control in managing cardiovascular events was consistent in different AIP subgroups.

\section{Background}

Dyslipidemia is one of the known risk factors for cardiovascular diseases, which is the main cause of morbidity and mortality worldwide. The atherogenic index of plasma (AIP), calculated by the logarithm of the ratio between the level of triglyceride (TG) and high-density lipoprotein cholesterol (HDL-C), is an indicator reflecting the characteristics and the degree of abnormal lipid metabolism. ${ }^{1}$ Previous studies revealed that AIP was associated with the risks of several cardiovascular diseases, such as incident ischemic heart disease, atherosclerosis, coronary artery disease, acute ischemic stroke, etc. ${ }^{2-4}$ However, previous studies have been mainly focusing on the general population. To our knowledge, information on the association between AIP with the risk of major adverse cardiovascular events (MACEs) among nondiabetic hypertensive elderly patients is very limited.

Compared with standard blood pressure control (<140/90 mm Hg), intensive blood pressure control $(<120 / 80 \mathrm{~mm} \mathrm{Hg}$ ) has shown significantly better cardiovascular outcomes according to the results from the Systolic Blood Pressure Intervention Trial (SPRINT). ${ }^{5}$ It is less known whether the association between AIP and MACEs is independent of standard or intensive blood pressure control. Therefore, in this study, 
we aim to explore the predictive value of AIP on the risk of MACEs among non-diabetic hypertensive elderly patients and to evaluate whether the benefit of intensive blood pressure control in preventing MACEs is stable in different AIP subgroups.

\section{Methods}

\subsection{Study population and design}

Data used in this analysis was derived from the SPRINT dataset, available at National, Heart, Lung, and Blood Institute data repository in the Biologic Specimen and Data Repository Information Coordinating Center (BioLINCC). SPRINT was a randomized, controlled, open-label trial conducted at 102 clinical sites in the United States and approved by all institutional review boards involved in the participating centers. The protocol and main outcomes have previously been published. ${ }^{5,6}$ The primary outcome was that in patients with hypertension at high cardiovascular risk, intensive BP control could significantly reduce the rate of the composite cardiovascular outcomes and all-cause mortality compared with standard BP control.

The main aim of this analysis is to assess the association between baseline atherogenic index of plasma (calculated by triglycerides and HDL cholesterol) and the composite cardiovascular outcomes in the SPRINT participants. We excluded 38 subjects with missing baseline triglycerides and HDL cholesterol and 9,323 participants were included in the final analysis.

\subsection{Evaluation of atherogenic index of plasma and Study outcomes}

The atherogenic index of plasma was calculated by the logarithm of TG/HDL-C mole ratio base 10 . The adopted conversion factors were TG: $1 \mathrm{ng} / \mathrm{dL}=0.011 \mathrm{mmol} / \mathrm{L}, \mathrm{HDL}-\mathrm{C}: 1 \mathrm{ng} / \mathrm{dL}=0.026 \mathrm{mmol} / \mathrm{L} .9,323$ participants were grouped according to AIP quartiles: Q1 ( $n=2331)$, Q2 ( $n=2329)$, Q3 $(n=2330), Q 4$ $(n=2333)$. The Q1 group was used as the reference.

The primary outcome of this analysis was the composite cardiovascular outcomes, including myocardial infarction (MI), no-Ml acute coronary syndrome, stroke, cardiovascular mortality, and heart failure. The definition of the outcomes has been published in the SPRINT protocol. ${ }^{6}$

\subsection{Statistical analysis}

Participants were grouped by the AIP quartiles. Continuous variables were expressed as mean (standard deviation) or median (Q1-Q3) based on the distribution of data. The difference between the quartiles were tested using ANOVA and Kruskal-Wallis $\mathrm{H}$ test for normal distribution data and skew distribution data 
respectively. All categorical variables were expressed as frequency (percentile). Chi-square test or Fisher test were used to test the difference of categorical variables between groups.

We performed the Cox model to assess the association between AIP quartiles and the occurrence of the primary outcome in three models. The model was adjusted for none. Model 2 was adjusted for age, race, and treatment arms. Model 3 was adjusted for age, race, treatment arms, body mass index, systolic blood pressure, heart rate, smoking status, serum creatinine, fasting total cholesterol, fasting glucose, previous CVD, previous CKD, aspirin use, and statin use. The Schoenfeld residuals test was used to test the proportional hazard assumption in the Cox model. The robustness of the association between AIP and primary outcome was evaluated in prescribed subgroups using subgroup analysis and interaction test. To establish the relationship between AIP and the effect of intensive BP control for the risk of the primary outcome, $\mathrm{P}$ for interaction was calculated. The model was adjusted for all covariates in Model 3 except treatment arms. Poisson regression was used to assess the incidence of primary outcomes by treatment arms and AIP quartiles.

All analyses were performed using the statistical software packages R (The R Foundation; http://www.Rproject.org). Statistical significance was set at $P<0.05$.

\section{Results}

\subsection{Baseline characteristics of the participants}

9,323 participants with AIP were included in this analysis, and 561(6.02\%) participants had composite cardiovascular outcomes during a median of 3.22 years of follow-up. The baseline characteristics of the included subjects according to the AIP quartiles were shown in Table 1. Participants in higher quartiles of AIP had a higher body mass index, diastolic blood pressure, heart rate, serum creatinine, fasting triglycerides, glucose, and cardiovascular risk than in lower quartiles. Subjects in higher quartiles were more likely to be $<75$ years of age, male, and current smokers. Compared with participants in lower quartiles, subjects in higher quartiles were more likely to have chronic kidney disease and a higher rate of composite cardiovascular outcomes.

\subsection{Relationship between AIP and primary outcome}

Table 2 presented the HRs $(95 \% \mathrm{Cl})$ of primary outcome among the included participants grouped by quartiles of AIP. The subjects in the highest quartile of AIP had a significantly increased risk of the primary outcome. The association persisted even after adjusting for potential confounding factors, including age, race, treatment arms, body mass index, systolic blood pressure, heart rate, smoking status, serum creatinine, fasting total cholesterol, fasting glucose, previous CVD, previous CKD, aspirin use and statin use. In the fully adjusted Model 3, the adjusted HRs of the primary outcome for participants in Q2, Q3, and Q4 of AIP were 1.32 $(1.02,1.72), 1.38(1.05,1.81)$, and $1.56(1.17,2.08)$ respectively. Consistently, the trend test for the association between AIP quartiles and the primary outcome showed that a higher 
AIP quartile was associated with a significantly higher risk of the primary outcome (adjusted $\mathrm{HR}(95 \% \mathrm{Cl})$ in Model 3: $1.14(1.04,1.25), P=0,004)$.

\subsection{Subgroup analysis for the risk of primary outcome by baseline AIP quartiles}

The stratified analyses were performed to assess the impact of AIP (per 1 quartile increment) on the risk of the primary outcome. As shown in Table 3, the relationship between AIP and the primary outcome was consistent in prescribed stratifications: sex (male vs. female), age (<75 years vs. >=75 years), race (black vs. non-black), previous CVD (yes vs. no), previous CKD (yes vs. no), Framingham 10-y CVD risk (<15\% vs. $>=15 \%$ ), aspirin use (yes vs. no) and statin use (yes vs. no). All P for interaction was $>0.05$.

\subsection{Intensive blood pressure control and primary outcome according to AIP quartiles}

Results stratified by AIP quartiles showed higher event rates with increasing frailty in both treatment groups (Figure 1). However, within each AIP quartile, absolute event rates were lower for the intensive treatment group. No evidence was found for the interaction of intensive blood pressure control and AIP for the risk of the primary outcome $(P$ for interaction $=0.932)$.

\section{Discussion}

This secondary analysis of the SPRINT data found that among hypertensive elderly patients, higher AIP was associated with a significantly higher risk of composite cardiovascular outcomes. The benefit of intensive blood pressure control on composite cardiovascular outcomes was consistent in different AIP quartiles. No evidence was found for the interaction of intensive blood pressure control and AIP for the risk of the primary outcome.

Previous studies observed a positive association between AIP and the risk of MACEs in different populations. A fifteen-year cohort study on healthy adults revealed the value of AIP in the prediction of developing cardiovascular events and its-related mortality. ${ }^{7}$ Results of a study on the Iran population indicated AIP to be positively associated with the risk of cardiovascular diseases. ${ }^{8}$ A cohort study among postmenopausal Chinese women (aged over 50) concluded that AIP was an independent predictor of cardiovascular risk. A study on the Health Risk Assessment Study and Korea Health Insurance Review and Assessment Service (HERAS-HIRA) cohort found that the higher the AIP quartile, the higher the incidence of ischemic heart disease. ${ }^{2}$ In the elderly population, those with a higher baseline blood pressure have a higher Framingham score, which represents a higher cardiovascular risk. Although a large body of evidence has proven the positive association between AIP and the risk of MACEs, this association was not fully discovered and needs to be studied in elderly patients with hypertension. 
Consistent with previous studies, in this study, we found elevated AIP to be positively associated with a higher risk of MACEs in non-diabetic elderly patients with hypertension.

TG level was suggested to be positively associated with a higher prevalence of cardiovascular outcomes. ${ }^{9}$ Within the high TG level, low HDL-C levels showed a higher risk of cardiovascular disease compared to people with low HDL-C levels. ${ }^{10}$ Increases in TG levels and decreases in HDL levels are both strong indicators of cardiovascular risk. This mechanism may explain why elevated AIP as a parameter of blood lipid levels has a strong correlation with increased risk of MACEs. In addition, a previous study found AIP level was correlated with the degree of insulin resistance, which indicated the degree of abnormal glucose metabolism. ${ }^{11}$ Insulin resistance and related hyperinsulinemia, hyperglycemia, as well as adipocytokines, may also cause vascular endothelial dysfunction, dyslipidemia, hypertension, and vascular inflammation, all of which contribute to the development of cardiovascular diseases.

According to a 9-year longitudinal study in Taiwan, AIP was proven to be significantly positively correlated with the prevalence of hypertension. ${ }^{12}$ A longitudinal study following a cohort of Hanzhong hypertensive adolescents for 12 years found that a high AIP level was a strong risk factor of hypertension-associated renal damage. ${ }^{13}$ With a growing body of evidence showing a linear relationship between blood pressure and the risk of cardiovascular diseases, the benefits of intensive blood pressure control in decreasing MACEs risks have already been proven in older patients with hypertension. ${ }^{14,15}$ Therefore, we evaluated the relationship between AIP and the effect of intensive blood pressure control for the risk of cardiovascular diseases and found the benefit of intensive blood pressure control is consistent in different AIP quartiles and no interaction of intensive blood pressure control and AIP for the risk of primary outcome was found.

Some limitations in this study should be addressed. First, the SPRINT trial did not define AIP subgroups, which limited the expansion of the results. Second, some AIP-related data, such as waist circumference and diet, cannot be acquired, while these data may alter the study results. Furthermore, an optimal cut-off value of AIP in predicting MACE risk remains to be determined for better risk stratification in clinical settings. Therefore, future investigations are necessary to evaluate the clinical application of AIP in nondiabetic elderly patients with hypertension.

\section{Conclusions}

In conclusion, this study found that elevated AIP is independently and positively associated with the risk of MACEs among non-diabetic elderly hypertensive patients. The benefit of intensive blood pressure control in managing cardiovascular events was consistent in different AIP subgroups. There is no need to pay too much attention to AIP when treating elderly hypertensive patients with intensive blood pressure regimen in clinical settings.

\section{Abbreviations}


AIP: atherogenic index of plasma

MACEs: major adverse cardiovascular events

SPRINT: Systolic Blood Pressure Intervention Trial

TG: triglyceride

HDL-C: triglyceride and high-density lipoprotein cholesterol

Ml: myocardial infarction

HERAS-HIRA: Health Risk Assessment Study and Korea Health Insurance Review and Assessment Service

\section{Declarations}

\section{Ethics approval and consent to participate}

Not applicable.

\section{Consent for publication}

Not applicable.

\section{Availability of data and materials}

The dataset supporting the conclusions of this article is available in the Biologic Specimen and Data Repository Information Coordinating Center (BioLINCC) repository, hyperlink to dataset in https://biolincc.nhlbi.nih.gov/home/.

\section{Competing interests}

The authors declare that they have no competing interests.

\section{Funding}

This study was supported by the Fundamental Research Funds for Central Universities of Central South University (unique identifier: 2020zzts876).

\section{Author's contributions}

$\mathrm{FH}$ and $\mathrm{JC}$ completed the writing of the paper. $\mathrm{KZ}$ applied for the database and made statistical analysis. $Z W$ and $Y W$ were responsible for the revision of the paper. All authors confirmed the final version of the paper.

\section{Acknowledgements}


Not applicable.

\section{References}

1. Dobiasova $M$, Frohlich J. The plasma parameter log (TG/HDL-C) as an atherogenic index: correlation with lipoprotein particle size and esterification rate in apoB-lipoprotein-depleted plasma (FER(HDL)). Clin Biochem. 2001;34:583-8.

2. Kim JJ, Yoon J, Lee YJ, Park B, Jung DH. Predictive value of the atherogenic index of plasma (AIP) for the risk of incident ischemic heart disease among non-diabetic Koreans. Nutrients. 2021;13.

3. Liu H, Liu K, Pei L, Li S, Zhao J, Zhang K, Zong C, Zhao L, Fang H, Wu J, Sun S, Song B, Xu Y, Gao Y. Atherogenic index of plasma predicts outcomes in acute ischemic stroke. Front Neurol. 2021;12:741754.

4. Shimizu Y, Nakazato M, Sekita T, Kadota K, Yamasaki H, Takamura N, Aoyagi K, Maeda T. Association of arterial stiffness and diabetes with triglycerides-to-HDL cholesterol ratio for Japanese men: the Nagasaki Islands Study. Atherosclerosis. 2013;228:491-5.

5. Group SR, Wright JT, Jr., Williamson JD, Whelton PK, Snyder JK, Sink KM, Rocco MV, Reboussin DM, Rahman M, Oparil S, Lewis CE, Kimmel PL, Johnson KC, Goff DC, Jr., Fine LJ, Cutler JA, Cushman WC, Cheung AK, Ambrosius WT. A randomized trial of intensive versus standard blood-pressure control. N Engl J Med. 2015;373:2103-16.

6. Ambrosius WT, Sink KM, Foy CG, Berlowitz DR, Cheung AK, Cushman WC, Fine LJ, Goff DC, Jr., Johnson KC, Killeen AA, Lewis CE, Oparil S, Reboussin DM, Rocco MV, Snyder JK, Williamson JD, Wright JT, Jr., Whelton PK, Group SSR. The design and rationale of a multicenter clinical trial comparing two strategies for control of systolic blood pressure: the Systolic Blood Pressure Intervention Trial (SPRINT). Clin Trials. 2014;11:532-46.

7. Sadeghi M, Heshmat-Ghahdarijani K, Talaei M, Safaei A, Sarrafzadegan N, Roohafza H. The predictive value of atherogenic index of plasma in the prediction of cardiovascular events; a fifteenyear cohort study. Adv Med Sci. 2021;66:418-423.

8. Hamzeh B, Pasdar Y, Mirzaei N, Faramani RS, Najafi F, Shakiba E, Darbandi M. Visceral adiposity index and atherogenic index of plasma as useful predictors of risk of cardiovascular diseases: evidence from a cohort study in Iran. Lipids Health Dis. 2021;20:82.

9. Alizargar J, Bai CH, Hsieh NC, Wu SV. Use of the triglyceride-glucose index (TyG) in cardiovascular disease patients. Cardiovasc Diabetol. 2020;19:8.

10. Jeppesen J, Hein HO, Suadicani P, Gyntelberg F. Triglyceride concentration and ischemic heart disease: an eight-year follow-up in the Copenhagen Male Study. Circulation. 1998;97:1029-36.

11. Tan $\mathrm{MH}$, Johns D, Glazer NB. Pioglitazone reduces atherogenic index of plasma in patients with type 2 diabetes. Clin Chem. 2004;50:1184-8.

12. Li YW, Kao TW, Chang PK, Chen WL, Wu LW. Atherogenic index of plasma as predictors for metabolic syndrome, hypertension and diabetes mellitus in Taiwan citizens: a 9-year longitudinal study. Sci 
Rep. 2021;11:9900.

13. Yuan Y, Hu JW, Wang Y, Wang KK, Zheng WL, Chu C, Ma Q, Yan Y, Liao YY, Mu JJ. Association between atherogenic index of plasma and subclinical renal damage over a 12-year follow-up: Hanzhong adolescent hypertension study. Eur J Clin Nutr. 2020;74:278-284.

14. Flack JM, Adekola B. Blood pressure and the new ACC/AHA hypertension guidelines. Trends Cardiovasc Med. 2020;30:160-164.

15. Bavishi C, Bangalore S, Messerli FH. Outcomes of intensive blood pressure lowering in older hypertensive patients. J Am Coll Cardiol. 2017;69:486-493.

\section{Tables}

Table 1. Baseline characteristic of the participants included in the analysis according to AIP quartiles. 
Variable

AIP

$\mathrm{P}$

\begin{tabular}{|c|c|c|c|c|c|}
\hline & & \multirow{2}{*}{ value } \\
\hline & Q1 & Q2 & Q3 & Q4 & \\
\hline $\mathrm{N}$ & 2331 & 2329 & 2330 & 2333 & \\
\hline AIP, mean (SD) & $-0.39(0.12)$ & $-0.13(0.05)$ & $0.05(0.06)$ & $0.35(0.17)$ & $<0.001$ \\
\hline Female, n (\%) & $\begin{array}{l}1056 \\
(45.30 \%)\end{array}$ & $\begin{array}{l}891 \\
(38.26 \%)\end{array}$ & $\begin{array}{l}760 \\
(32.62 \%)\end{array}$ & $\begin{array}{l}600 \\
(25.72 \%)\end{array}$ & $<0.001$ \\
\hline \multicolumn{6}{|l|}{ Treatment } \\
\hline Intensive, n (\%) & $\begin{array}{l}1168 \\
(50.11 \%)\end{array}$ & $\begin{array}{l}1173 \\
(50.36 \%)\end{array}$ & $\begin{array}{l}1171 \\
(50.26 \%)\end{array}$ & $\begin{array}{l}1150 \\
(49.29 \%)\end{array}$ & 0.882 \\
\hline BMI(Kg/m2), median (Q1-Q3) & $\begin{array}{l}28.03 \\
(5.72)\end{array}$ & $\begin{array}{l}29.62 \\
(5.76)\end{array}$ & $\begin{array}{l}30.59 \\
(5.89)\end{array}$ & $\begin{array}{l}31.16 \\
(5.18)\end{array}$ & \\
\hline \multicolumn{6}{|l|}{ Age, y } \\
\hline Overall & $\begin{array}{l}70.01 \\
(9.53)\end{array}$ & $\begin{array}{l}68.44 \\
(9.41)\end{array}$ & $\begin{array}{l}67.66 \\
(9.19)\end{array}$ & $\begin{array}{l}65.51 \\
(8.98)\end{array}$ & $<0.001$ \\
\hline$\geq 75 y, n(\%)$ & $\begin{array}{l}871 \\
(37.37 \%)\end{array}$ & $\begin{array}{l}700 \\
(30.06 \%)\end{array}$ & $\begin{array}{l}615 \\
(26.39 \%)\end{array}$ & $\begin{array}{l}455 \\
(19.50 \%)\end{array}$ & $<0.001$ \\
\hline Race, n (\%) & & & & & $<0.001$ \\
\hline Non-Hispanic White & $\begin{array}{l}1207 \\
(51.78 \%)\end{array}$ & $\begin{array}{l}1303 \\
(55.95 \%)\end{array}$ & $\begin{array}{l}1382 \\
(59.31 \%)\end{array}$ & $\begin{array}{l}1494 \\
(64.04 \%)\end{array}$ & \\
\hline Non-Hispanic Black & $\begin{array}{l}919 \\
(39.43 \%)\end{array}$ & $\begin{array}{l}790 \\
(33.92 \%)\end{array}$ & $\begin{array}{l}622 \\
(26.70 \%)\end{array}$ & $\begin{array}{l}454 \\
(19.46 \%)\end{array}$ & \\
\hline Hispanic & $160(6.86 \%)$ & $201(8.63 \%)$ & $\begin{array}{l}280 \\
(12.02 \%)\end{array}$ & $\begin{array}{l}337 \\
(14.44 \%)\end{array}$ & \\
\hline Other & $45(1.93 \%)$ & $35(1.50 \%)$ & $46(1.97 \%)$ & $48(2.06 \%)$ & \\
\hline
\end{tabular}

Baseline blood pressure, $\mathrm{mm} \mathrm{Hg}$

\begin{tabular}{llllll} 
Systolic $(\mathrm{mm} \mathrm{Hg})$ & 140.94 & 139.82 & 139.20 & 138.71 & $<0.001$ \\
& $(16.03)$ & $(15.52)$ & $(15.58)$ & $(15.09)$ & \\
\hline Diastolic $(\mathrm{mm} \mathrm{Hg})$ & 77.15 & 78.00 & 77.85 & 79.51 & $<0.001$ \\
& $(12.42)$ & $(11.83)$ & $(11.45)$ & $(11.93)$ &
\end{tabular}

Distribution of systolic blood pressure, $\mathrm{n}(\%)$ $<0.001$

$\begin{array}{lllll}\leq 132 \mathrm{~mm} \mathrm{Hg} & 712 & 792 & 798 & 822 \\ & (30.54 \%) & (34.01 \%) & (34.25 \%) & (35.23 \%) \\ >132 \text { to }<145 \mathrm{~mm} \mathrm{Hg} & 738 & 738 & 771 & 779 \\ & (31.66 \%) & (31.69 \%) & (33.09 \%) & (33.39 \%) \\ \geq 145 \mathrm{~mm} \mathrm{Hg} & 881 & 799 & 761 & 732 \\ & (37.79 \%) & (34.31 \%) & (32.66 \%) & (31.38 \%)\end{array}$




\begin{tabular}{|c|c|c|c|c|c|}
\hline Baseline heart rate, bpm & $\begin{array}{l}65.39 \\
(11.33)\end{array}$ & $\begin{array}{l}65.79 \\
(11.44)\end{array}$ & $\begin{array}{l}66.11 \\
(11.72)\end{array}$ & $\begin{array}{l}67.61 \\
(11.82)\end{array}$ & \\
\hline Serum creatinine, $\mathrm{mg} / \mathrm{dL}$ & $1.04(0.32)$ & $1.07(0.32)$ & $1.07(0.34)$ & $1.12(0.37)$ & $<0.001$ \\
\hline $\begin{array}{l}\text { Urine Albumin/Creatinine } \\
\text { ratio, mg/g Cr, median (Q1- } \\
\text { Q3) }\end{array}$ & $\begin{array}{l}9.84(5.86- \\
20.75)\end{array}$ & $\begin{array}{l}9.09(5.49- \\
19.97)\end{array}$ & $\begin{array}{l}9.33(5.62- \\
22.82)\end{array}$ & $\begin{array}{l}9.71(5.57- \\
23.00)\end{array}$ & 0.047 \\
\hline $\begin{array}{l}\text { Estimated GFR, mL.min-1 } \\
1.73 \text { m-2, median (Q1-Q3) }\end{array}$ & $\begin{array}{l}72.32 \\
(59.75- \\
86.22)\end{array}$ & $\begin{array}{l}70.92 \\
(57.90- \\
83.91)\end{array}$ & $\begin{array}{l}71.84 \\
(58.38- \\
84.95)\end{array}$ & $\begin{array}{l}70.17 \\
(56.49- \\
83.44)\end{array}$ & $<0.001$ \\
\hline $\begin{array}{l}\text { Fasting total cholesterol, } \\
\mathrm{mg} / \mathrm{dL} \text {, median (Q1-Q3) }\end{array}$ & $\begin{array}{l}187.00 \\
(162.00- \\
214.00)\end{array}$ & $\begin{array}{l}183.00 \\
(158.00- \\
209.00)\end{array}$ & $\begin{array}{l}185.00 \\
(158.00- \\
212.00)\end{array}$ & $\begin{array}{l}193.00 \\
(168.00- \\
223.00)\end{array}$ & $<0.001$ \\
\hline $\begin{array}{l}\text { Fasting total triglycerides, } \\
\mathrm{mg} / \mathrm{dL} \text {, median (Q1-Q3) }\end{array}$ & $\begin{array}{l}63.00 \\
(54.00- \\
74.00)\end{array}$ & $\begin{array}{l}90.00 \\
(80.00- \\
104.00)\end{array}$ & $\begin{array}{l}123.00 \\
(109.00- \\
138.00)\end{array}$ & $\begin{array}{l}194.00 \\
(162.00- \\
242.00)\end{array}$ & $<0.001$ \\
\hline $\begin{array}{l}\text { Fasting HDL cholesterol, } \\
\mathrm{mg} / \mathrm{dL} \text {, median (Q1-Q3) }\end{array}$ & $\begin{array}{l}66.00 \\
(57.00- \\
76.00)\end{array}$ & $\begin{array}{l}53.00 \\
(48.00- \\
60.00)\end{array}$ & $\begin{array}{l}47.00 \\
(42.00- \\
53.00)\end{array}$ & $\begin{array}{l}40.00 \\
(36.00- \\
46.00)\end{array}$ & $<0.001$ \\
\hline $\begin{array}{l}\text { Fasting glucose, mg/dL, } \\
\text { median (Q1-Q3) }\end{array}$ & $\begin{array}{l}95.00 \\
(89.00- \\
101.00)\end{array}$ & $\begin{array}{l}96.00 \\
(90.00- \\
104.00)\end{array}$ & $\begin{array}{l}98.00 \\
(91.00- \\
106.00)\end{array}$ & $\begin{array}{l}100.00 \\
(93.00- \\
109.00)\end{array}$ & $<0.001$ \\
\hline Statin use, $\mathrm{n}(\%)$ & $\begin{array}{l}916 \\
(39.65 \%)\end{array}$ & $\begin{array}{l}1042 \\
(44.99 \%)\end{array}$ & $\begin{array}{l}1081 \\
(46.76 \%)\end{array}$ & $\begin{array}{l}1007 \\
(43.33 \%)\end{array}$ & $<0.001$ \\
\hline Aspirin use, $\mathrm{n}(\%)$ & $\begin{array}{l}1182 \\
(50.86 \%)\end{array}$ & $\begin{array}{l}1197 \\
(51.42 \%)\end{array}$ & $\begin{array}{l}1224 \\
(52.65 \%)\end{array}$ & $\begin{array}{l}1144 \\
(49.16 \%)\end{array}$ & 0.120 \\
\hline Smoking status, n (\%) & & & & & 0.006 \\
\hline Never smoked & $\begin{array}{l}1088 \\
(46.68 \%)\end{array}$ & $\begin{array}{l}1031 \\
(44.27 \%)\end{array}$ & $\begin{array}{l}1024 \\
(43.95 \%)\end{array}$ & $\begin{array}{l}968 \\
(41.49 \%)\end{array}$ & \\
\hline Former smoker & $\begin{array}{l}964 \\
(41.36 \%)\end{array}$ & $\begin{array}{l}994 \\
(42.68 \%)\end{array}$ & $\begin{array}{l}1006 \\
(43.18 \%)\end{array}$ & $\begin{array}{l}999 \\
(42.82 \%)\end{array}$ & \\
\hline Current smoker & $\begin{array}{l}276 \\
(11.84 \%)\end{array}$ & $\begin{array}{l}302 \\
(12.97 \%)\end{array}$ & $\begin{array}{l}296 \\
(12.70 \%)\end{array}$ & $\begin{array}{l}364 \\
(15.60 \%)\end{array}$ & \\
\hline $\begin{array}{l}\text { Framingham 10-y CVD risk } \\
\text { score, \%, median (Q1-Q3) }\end{array}$ & $\begin{array}{l}14.71 \\
(10.27- \\
21.61)\end{array}$ & $\begin{array}{l}16.80 \\
(11.33- \\
24.24)\end{array}$ & $\begin{array}{l}18.49 \\
(12.68- \\
26.77)\end{array}$ & $\begin{array}{l}21.39 \\
(15.08- \\
30.26)\end{array}$ & $<0.001$ \\
\hline Previous CVD, n (\%) & $\begin{array}{l}420 \\
(18.02 \%)\end{array}$ & $\begin{array}{l}466 \\
(20.01 \%)\end{array}$ & $\begin{array}{l}502 \\
(21.55 \%)\end{array}$ & $\begin{array}{l}481 \\
(20.62 \%)\end{array}$ & 0.021 \\
\hline Previous CKD, n (\%) & $\begin{array}{l}596 \\
(25.57 \%)\end{array}$ & $\begin{array}{l}673 \\
(28.90 \%)\end{array}$ & $\begin{array}{l}641 \\
(27.51 \%)\end{array}$ & $\begin{array}{l}735 \\
(31.50 \%)\end{array}$ & $<0.001$ \\
\hline Primary outcome & $103(4.42 \%)$ & 137 (5.88\%) & $150(6.44 \%)$ & $171(7.33 \%)$ & $<0.001$ \\
\hline
\end{tabular}


AIP: atherogenic index of plasma.

Table 2. Association between AIP and primary outcome in different models.

\begin{tabular}{|c|c|c|c|}
\hline \multirow[t]{2}{*}{ AIP quartiles } & Model 1 & Model 2 & Model 3 \\
\hline & \multicolumn{3}{|c|}{$\mathrm{HR}(95 \% \mathrm{Cl}) \mathrm{P}$ value } \\
\hline 1 & Ref. & Ref. & Ref. \\
\hline 2 & $\begin{array}{l}1.33(1.03,1.72) \\
P=0.027\end{array}$ & $\begin{array}{l}1.46(1.13,1.89) \\
P=0.004\end{array}$ & $\begin{array}{l}1.32(1.02,1.72) \\
P=0.037\end{array}$ \\
\hline 3 & $\begin{array}{l}1.45(1.13,1.86) \\
P=0.004\end{array}$ & $\begin{array}{l}1.68(1.31,2.17) \\
P<0.001\end{array}$ & $\begin{array}{l}1.38(1.05,1.81) \\
P=0.020\end{array}$ \\
\hline 4 & $\begin{array}{l}1.65(1.29,2.10) \\
P<0.001\end{array}$ & $\begin{array}{l}2.16(1.68,2.78) \\
P<0.001\end{array}$ & $\begin{array}{l}1.56(1.17,2.08) \\
P=0.003\end{array}$ \\
\hline $\begin{array}{l}\mathrm{P} \text { for trend (1 Q } \\
\text { increment) }\end{array}$ & $\begin{array}{l}1.16(1.08,1.25) \\
P<0.001\end{array}$ & $\begin{array}{l}1.27(1.18,1.38) \\
P<0.001\end{array}$ & $\begin{array}{l}1.14(1.04,1.25) \\
P=0.004\end{array}$ \\
\hline
\end{tabular}

Model were adjusted for none. Model 2 were adjusted for age, race and treatment arms. Model 3 were adjusted for age, race, treatment arms, body mass index, systolic blood pressure, heart rate, smoking status, serum creatinine, fasting total cholesterol, fasting glucose, previous CVD, previous CKD, aspirin use and statin use.

Table 3. Subgroup analysis for the risk of primary outcome by baseline AIP quartiles ( 1 quartile increment). 
AIP Quartiles (1 Q increment)

\begin{tabular}{|c|c|c|c|}
\hline Subgroup & $\mathrm{HR}, 95 \% \mathrm{Cl}$ & $P$ value & $P$ for interaction \\
\hline Sex & & & 0.336 \\
\hline Male & $1.67(1.11,2.52)$ & 0.014 & \\
\hline Female & $1.28(0.80,2.05)$ & 0.305 & \\
\hline Age group & & & 0.816 \\
\hline$<75$ & $1.31(0.89,1.92)$ & 0.174 & \\
\hline >=75 & $1.39(0.91,2.11)$ & 0.129 & \\
\hline Race & & & 0.398 \\
\hline Black & $1.34(0.77,2.31)$ & 0.302 & \\
\hline No-black & $1.72(1.20,2.47)$ & & \\
\hline Previous CVD & & & 0.932 \\
\hline Yes & $1.62(1.01,2.58)$ & 0.044 & \\
\hline No & $1.65(1.14,2.40)$ & 0.008 & \\
\hline Previous CkD & & & 0.981 \\
\hline Yes & $1.65(1.04,2.61)$ & 0.034 & \\
\hline No & $1.64(1.13,2.38)$ & 0.01 & \\
\hline CVD RISK & & & 0.423 \\
\hline$<15 \%$ & $1.47(0.88,2.46)$ & 0.141 & \\
\hline$>=15 \%$ & $1.86(1.27,2.72)$ & 0.001 & \\
\hline Aspirin Use & & & 0.912 \\
\hline Yes & $1.66(1.13,2.43)$ & 0.009 & \\
\hline No & $1.61(1.03,2.52)$ & 0.035 & \\
\hline Statin Use & & & 0.350 \\
\hline Yes & $1.84(1.22,2.77)$ & 0.003 & \\
\hline No & $1.45(0.96,2.19)$ & 0.074 & \\
\hline
\end{tabular}

Model were adjusted for all covariates in Model 3 except stratifications itself.

Figures 


\section{Intensive BP control}

Event, n/N Event Rate/1000 pr

\section{Standard BP control}

Event,n/N Event Rate/1000 pr

$\mathrm{HR}(95 \%)$

$P$ value $P$ for interaction

AIP Quartiles

Q1

Q2

Q3

Q4

$43 / 1168 \quad 12(2,477)$

$58 / 1173$

$16(3,637)$

$68 / 1171$

$74 / 1150$
$18(3,736)$

$20(3,805)$

(1)

\begin{tabular}{|c|c|c|c|c|}
\hline $60 / 1163$ & $17(3,663)$ & - & $0.65(0.44,0.97)$ & 0.036 \\
\hline $79 / 1156$ & $22(4,877)$ & & $0.73(0.52,1.03)$ & 0.073 \\
\hline $82 / 1159$ & $23(4,906)$ & & $0.78(0.56,1.08)$ & 0.141 \\
\hline $97 / 1183$ & $26(5,1055)$ & & $0.73(0.54,0.99)$ & 0.044 \\
\hline
\end{tabular}

0.923

\section{Figure 1}

Intensive BP control and primary outcome according to AIP quartiles.

*pr: person year. Model were adjusted for all covariates in Model 3 except treatment arms. 